\title{
A SOCIALIZAÇÃO ENTRE PARES E AS EXPERIÊNCIAS PREGRESSAS: ELEMENTOS FACILITADORES PARA OS PROFESSORES INICIANTES DA EDUCAÇÃO INFANTIL
}

\author{
SOLANGE CARDOSO ${ }^{1}$, CÉLIA NUNES ${ }^{2}$.
}

\begin{abstract}
${ }^{1}$ Doutoranda no Programa de Pós-graduação em Educação da Faculdade de Educação da Universidade de Brasília(PPGE/FE/UNB), membro do Grupo de Estudos e Pesquisas sobre Formação e Atuação de Professores/Pedagogos (GEPFAPe). Mestre em Educação pela Universidade Federal de Ouro Preto(2013).solangecardoso1908@gmail.com

2 Pós-Doutora pela Universidade Federal de Minas Gerais ( 2010), Doutora em Educação pela Pontifícia Universidade Católica do Rio de Janeiro (2004), é Professora Associada da Universidade Federal de Ouro Preto atuando na Graduação e Pós- Graduação. E vice Lider do Grupo de Pesquisa sobre Formação e Profissão Docente (FOPROFI/DEEDU/UFOP), membro do Grupo de Pesquisas sobre Condição e Formação Docente (PRODOC /FAE/UFMG), membro da Red Docente de América Latina y el Caribe (KIPUS) e Rede Latinoamericana de Estudos Sobre Trabalho Docente (Rede ESTRADO). celia@ufop.edu.br.
\end{abstract}

\section{RESUMO}

O crescimento quantitativo das pesquisas sobre formação de professores tem sido acompanhado também por um crescimento qualitativo, em que podemos observar a preocupação em abordar diferentes temas que procuram conhecer cada vez melhor os diversos aspectos que estão relacionados aos docentes, entre estes, o professor principiante. Autores como Garcia (1999) e Lima (2004) têm apontado, em seus estudos, a importância da investigação de aspectos relativos à etapa de iniciação na carreira docente, haja vista que, para eles, essa é a etapa mais importante no desenvolvimento da carreira docente, mas também a mais complexa, marcada por momentos de tensão e dúvidas diante de uma fase cheia de novidades. Este estudo tem como objetivo apresentar alguns elementos facilitadores no início da carreira docente, a partir dos dados de um estudo concluído no Programa de Pós Graduação em Educação na Universidade Federal de Ouro Preto, sobre os desafios da docência das professoras iniciantes da Educação Infantil da Região dos Inconfidentes, cujo problema investigado refere-se ao modo como os professores principiantes vivenciam os desafios do início da docência. Como referencial metodológico, desenvolveu-se uma pesquisa de abordagem predominantemente qualitativa. Para a coleta de dados, optou-se por utilizar o questionário, a observação e a entrevista semiestruturada com um grupo de professoras selecionado a partir de critérios previamente definidos, qual seja, ser professor iniciante, com até 5 anos de carreira na Educação Infantil. Os dados da pesquisa apontaram que a socialização dos professores iniciantes, as experiências pregressas com a sala de aula e os estágios foram apresentados como fatores facilitadores no início da carreira docente. Apontaram ainda que essa rede de relações no cotidiano, na qual a socialização ocorre com diversos sujeitos da escola e fora dela, favorece para que os professores aprendam sobre o trabalho docência de forma menos sofrida. 
Palavras-chave: Educação Infantil; Experiências pregressas; Professor iniciante; Socialização entre pares.

\title{
SOCIALIZATION BETWEEN COUPLES AND PREGRESSED EXPERIENCES: FACILITATING ELEMENTS FOR CHILDREN'S EDUCATION TEACHING TEACHERS
}

\begin{abstract}
The quantitative growth of research on teacher training has also been accompanied by a qualitative growth, in which we can observe the concern in addressing different themes that seek to know better and better the different aspects that are related to teachers, among them, the beginning teacher. Authors such as Marcelo Garcia (1999) and Lima (2004), have pointed out in their studies the importance of investigating aspects related to the initiation stage in the teaching career, given that for them this is the most important stage in the development of the teaching career, but also the most complex, marked by moments of tension and doubts in the face of a phase full of news. This study aims to present some facilitating elements at the beginning of the teaching career, based on data from a study completed in the Graduate Program in Education at the Federal University of Ouro Preto, on the teaching challenges of beginning teachers of Early Childhood Education in the Region of the Inconfidentes, whose problem investigated refers to the way in which the beginning teachers experience the challenges of the beginning of teaching. As a methodological framework, we developed a research with a predominantly qualitative approach. For data collection we chose to use the questionnaire, observation and semi-structured interview with a group of teachers selected from previously defined criteria, that is, being a beginner teacher with up to 5 years of career in Early Childhood Education. The research data pointed out that the socialization of beginning teachers, past experiences with the classroom and internships were presented as facilitating factors in the beginning of the teaching career. And they pointed out that this network of relationships in daily life, where socialization occurs with different school subjects and outside it, favors for teachers to learn about teaching work in a less painful way.
\end{abstract}

Keywords: Beginning teacher; Child education; Peer socialization; Past experiences.

\section{DANDO VOZ AS PROFESSORAS INICIANTES...}

(1) "[...] aí eu fui perdendo o medo e fui começando a perguntar um monte de coisas pra elas, aí ficou mais fácil de trabalhar"( Cássia).

(2) "[...] o que você vê em sala de aula não é a prática, nunca é, porque quando eu fiz faculdade era muito mar de rosas, a prática é totalmente diferente e quando eu fui fazer estágio eu realmente vi como é a prática" (Tânea). 
Os excertos acima, extraídos de falas de professoras, ao relatar seus primeiros dias como docentes, faz-nos observar que tensões e desafios estão presentes no princípio de qualquer atividade profissional e isso não é diferente quando falamos de professores. Sentimentos diversos como angústia, medo, entusiasmo e disposição diante do novo florescem na prática cotidiana docente. Partimos desses excertos para apresentar o tema deste estudo e justificá-lo como sendo também um tema de "necessidade indiscutivel" dentro do campo educacional que investiga a Formação de Professores. Como destaca Marcelo Garcia (1998), houve uma mudança na preocupação nos estudos que, inicialmente, focavam a formação dos professores passando para o desenvolvimento de pesquisas a respeito dos professores principiantes e dos professores em exercício.

O crescimento quantitativo das pesquisas sobre formação de professores tem sido acompanhado também por um crescimento qualitativo, em que podemos observar a preocupação em abordar diferentes temas que procuram conhecer cada vez melhor os diversos aspectos que estão relacionados ao docente, entre este, o professor principiante.

Autores como Marcelo Garcia (1999) e Lima (2004) têm apontado, em seus estudos, a importância da investigação de aspectos relativos à etapa de iniciação na carreira docente, haja vista que, para eles, essa é a etapa mais importante no desenvolvimento da carreira docente, mas também a mais complexa, marcada por momentos de tensão e dúvidas diante de uma fase cheia de novidades.

Nos anos iniciais de inserção profissional, os professores passam por um período de tensões e aprendizagens intensivas em contextos desconhecidos e são cobrados a adquirir conhecimento profissional e ainda a conseguir manter um equilíbrio profissional e pessoal em um período de tempo muito breve (GARCIA, 1999).

Lima (2006) contribui nesse sentido, apontando que o início da docência é vivido como um período muito difícil e sofrido, e que este é apontado como um dos momentos que mais causam mal-estar nos professores. A referida autora ainda aponta que essa fase não tem recebido a atenção necessária por parte dos pesquisadores na área de formação de professores e que, sendo esta uma fase complexa, ainda há muito que se descobrir para que o início da carreira docente não seja tão sofrido.

Lichtenecker (2010) também notou essa pouca expressividade e ressaltou, em sua dissertação intitulada "Desenvolvimento profissional de professores principiantes e 
os movimentos para a assunção da profissão docente", que os estudos e as pesquisas que abordam o tema professores principiantes, no Brasil, ainda não ocuparam uma posição de destaque, sendo escassas e frágeis, apesar de muitos pesquisadores apontarem para a sua relevância.

Este estudo tem como objetivo apresentar alguns fatores facilitadores no início da carreira docente, a partir dos dados de uma pesquisa cujo problema investigado refere-se ao modo como os professores principiantes vivenciam os desafios do início da docência. Recorrendo aos dados da nossa pesquisa, notamos que a socialização dos professores iniciantes, as experiências com a sala de aula e os estágios foram apresentados como fatores facilitadores no início da carreira docente. Como referencial metodológico, desenvolveu-se uma pesquisa de abordagem predominantemente qualitativa. Para a coleta de dados, optou-se por utilizar o questionário, a observação e a entrevista semiestruturada a um grupo de professoras selecionado a partir de critérios previamente definidos, qual seja, ser professor iniciante, com até 5 anos de carreira, na Educação Infantil. A partir desses critérios, foram encontradas 14 (quatorze) professoras que atenderam o perfil da nossa pesquisa e aceitaram contribuir com nosso estudo, ressalta-se que o nome delas não foi divulgado, sendo utilizados nomes fictícios neste estudo.

\section{ELEMENTOS FACILITADORES NO INÍCIO DA DOCÊNCIA}

Devido a sentimentos comuns nessa fase do desenvolvimento profissional, como insegurança, medo, angústia e a falta de um direcionamento curricular para esse segmento, a maioria dos sujeitos da pesquisa tinham como prática constante recorrer aos professores mais experientes da escola, diretores e supervisores. E, em alguns momentos, recorriam também aos docentes fora da escola, como professores aposentados ou que trabalhavam em outras escolas.

O início da docência para as professoras participantes da pesquisa foi um momento de intensa aprendizagem e ocorreu, principalmente, por meio da socialização com seus pares, uma vez que

No cotidiano da sala de aula o professor defronta-se com múltiplas situações divergentes com as quais não aprendeu a lidar durante seu curso de formação. 
Essas situações estão além dos referenciais teóricos e técnicos e por isso o professor não consegue apoio direto nos conhecimentos adquiridos nos cursos de formação para lidar com elas (MIZUKAMI et al., 2002, p. 14).

Para Rita (nome fictício para preservar sua identidade e das outras professoras), a socialização ocorria também em momentos que ela se sentia insegura, "perdida", sem saber o que fazer diante de problemas que envolviam os alunos. Nessas situações, ela recorria principalmente à diretora, por ver nela a autoridade máxima da escola. No entanto, a diretora a aconselhou que procurasse resolver sozinha os problemas com seus alunos, porque assim ela estaria conquistando o respeito deles. Para Rita, isso foi um acontecimento muito marcante, pois ela acreditava que poderia continuar pedindo apoio sempre em todas as situações. No entanto, para Rita, essa atitude da diretora a deixou ainda mais insegura: “[...] como é que eu vou me virar? Tem que ter alguém- uma outra pessoa - para me falar se eu posso fazer isso ou se eu não posso. Pegar o menino e jogar pra fora de sala é fácil, mas todo dia eu ia fazer isso?"

Esses relatos evidenciam o que a literatura vem apontando, ou seja, o professor iniciante se sente inseguro e dependente de alguém para orientá-lo, pois o trabalho do professor na sala de aula é solitário e, ao mesmo tempo, inusitado. Exige que o professor tenha determinadas habilidades e saberes para enfrentar desafios imprevisíveis, bem como espera que ele tenha atitudes rápidas e reações imediatas para resolver um grande número de pequenos problemas do seu dia a dia (PERRENOUD, 1993).

Outra forma de socialização estava relacionada com as trocas que ocorriam entre os professores que não trabalhavam na escola. As professoras Sueli e Tânea relataram que recorriam às professoras que já tiveram alguma experiência com a Educação Infantil. Com elas, era possível tirar dúvidas, conversar sobre a rotina da sala de aula, pegar materiais emprestados e se orientar sobre o que deveriam fazer. A escolha por essas docentes que não estão na mesma escola está relacionada também com a admiração e o reconhecimento que as professoras têm por elas. Sueli disse que recorria a uma professora já aposentada, mas que durante muito tempo trabalhou com a Educação Infantil e desenvolveu um trabalho que ficou reconhecido em seu município. A professora Tânea também recorria a uma professora que já havia trabalhado com a Educação Infantil e, nessa troca, ela conseguia sugestões de atividades, orientações e 
também troca de experiências que ajudavam a amenizar o seu sentimento de angústia diante dos desafios da docência.

Outra forma de socialização estava relacionada com a colaboração e as trocas entre os professores mais experientes da escola. Com esses professores, a socialização era favorecida pelos encontros diários na escola. Por se mostrarem mais disponíveis e por estarem desempenhando a mesma função, não havia o receio de serem avaliados, eles viam esses professores como companheiros, ou seja, pessoas que podiam contar sempre.

Para Marta e Rita, a socialização ocorria ainda melhor quando havia empatia entre as professoras, pois facilitava a troca e o trabalho se desenvolvia melhor. Segundo Rita, no período da tarde, havia duas turmas de $1^{\circ}$ período e ela procurava planejar suas atividades junto com a professora da outra turma: "[...] igual hoje que é dia do meio ambiente, a gente já preparou tudo junto de acordo, para fazer direitinho, aí aproveitamos os tópicos de tudo e nosso trabalho vai seguindo." Rita diz ainda que: “[...] no princípio eu era muito insegura eu não fazia nada sem perguntar a outra professora." Marta reforça que a identificação entre as professoras facilita o trabalho, assim, é possível trabalhar junto, pois “[...] parece até que o que ela pensa eu penso sobre os alunos, houve essa conexão entre nós duas, então a gente trabalha junto, forma uma equipe mesmo".

Os dados da nossa pesquisa mostraram que a socialização entre os professores experientes da escola é a que mais satisfazia as professoras iniciantes. Isso porque se encontravam diariamente e podiam recorrer a elas durante a realização de uma atividade caso tivessem dúvida, sem ter que marcar horário e encontrar fora da escola. Havia uma grande troca de materiais, assim como mais compreensão sobre o que estavam precisando e até mesmo o que estavam sentindo. Segundo a professora Cássia:

(3) [...] ficava com um pouco de receio de perguntar para as minhas colegas e elas acharem, tipo assim "não sabe nada", aí eu ficava com um pouco de receio, mas depois acostumei com elas e vi que elas elas tinham facilidade de passar o que sabiam e gostavam de fazer isso também: de estar ensinando o que elas já sabiam. Aí eu comecei a pegar mais costume com elas e elas começaram a me ensinar o que eu precisava dentro da sala, de um cartaz, dava dicas. Aí eu fui perdendo o medo assim, o receio e fui começando a perguntar um monte de coisas pra elas, aí ficou mais fácil de trabalhar. 
Além disso, os professores experientes da escola apoiavam também as iniciantes em situações de dificuldades com equipamentos, como relata Rita: "[...] eu não sabia nem colocar folha no mimeografo, ela teve a maior paciência e me explicou dando várias dicas”, com atividades artísticas, como relata Luciana: “[...] na hora de fazer um painel, na hora de confeccionar alguma coisa para o mural da sala, na hora de fazer um envelope para entregar as atividades para os pais, é sempre ela que me ajuda".

Discutindo essa questão, Hargreaves (1998) explica que a colaboração e a colegialidade são estratégias frutuosas de fomento do desenvolvimento profissional dos professores, pois permite que estes aprendam uns com os outros, partilhando e desenvolvendo em conjunto as suas competências. Além disso, a confiança decorrente da partilha e do apoio colegial conduz a uma maior disponibilidade para fazer experiências e para correr riscos e, com estes, a um empenho dos docentes num aperfeiçoamento contínuo, enquanto parte integrante das suas obrigações profissionais.

Para Hargreaves (1998), as discussões sobre a colaboração e a colegialidade se apoiam numa perspectiva cultural no qual se evidenciam aquilo que é possuído e partilhado em comum nas relações humanas: os valores, os hábitos, as normas e as crenças, isto é, o conteúdo partilhado das culturas dos professores.

Para o referido autor, a socialização entre os professores pode assumir diferentes formas e apresentar diversas relações, tendendo a ser: espontâneas, voluntárias, orientadas para o desenvolvimento, difundidas no tempo e no espaço e imprevisíveis. São consideradas espontâneas quando a iniciativa parte dos próprios professores e são sustentas por eles, podendo ou não ser apoiadas pela administração escolar. Assumem uma forma voluntária quando os professores percebem o valor advindo de suas experiências, inclinação ou persuasão não coercitiva, favorecendo assim para a percepção de que trabalhar em conjunto é agradável e também produtivo. Tendem a ser orientadas para o desenvolvimento quando os professores trabalham em conjunto, principalmente, para desenvolver iniciativas próprias ou para atender a requerimentos de iniciativas externas, nos quais estão empenhados.

Nesta relação, é frequente os professores estabelecerem as tarefas e as finalidades do seu trabalho em conjunto ao invés de se reunirem para desenvolver os propósitos e os interesses dos outros. Já a socialização, tende a ser difundida no tempo e espaço, o trabalho é em grande parte desenvolvido em conjunto e tende a ser em 
encontros informais, discretos, breves, porém frequentes. Esses encontros não são regulados, mas fazem parte do modo como o trabalho do professor é desenvolvido na escola e podem assumir e se expressar de formas variadas, seja por meio de palavras, olhares, elogios, agradecimentos, sugestões de novas ideias, discussões informais sobre o trabalho, partilha de problemas e, até mesmo, encontros coletivos com os pais. São consideradas relações imprevisíveis quando os professores exercem discrição e controle sobre o que desenvolvem, mas há incerteza e imprevisibilidade quanto aos resultados.

A literatura vem apontando que os professores iniciantes se sentem inseguros, angustiados e ansiosos diante da situação nova que vivenciam nos primeiros anos da carreira. Acredita-se, assim como Garcia (1999), que os programas de inserção à docência poderão amenizar esses sentimentos e contribuir para que esses professores não se sintam "perdidos", sem saber o que fazer quando assumem uma sala de aula; no entanto, esses programas de inserção à docência ainda são pontuais no Brasil (GATTI $e t$ al., 2011).

Diante da realidade apontada por Gatti et al. (2011), no que se refere à falta de programas de inserção à docência, percebe-se conforme os dados da nossa pesquisa, que os professores apontam e identificam as experiências com a sala de aula vivenciadas antes de iniciar a graduação - e mesmo durante - e os estágios, como uma alternativa, como momentos que contribuem e facilitam o início da docência. Os relatos das professoras indicam que esses momentos vivenciados, antes de ingressar na carreira, contribuíram para que elas se sentissem mais seguras diante das atividades docentes, tanto no que se refere ao planejamento e à execução das aulas, quanto para resolver questões relacionadas às relações interpessoais. Para Tardif (2002), esses saberes construídos a partir de uma base de conhecimentos, somados aos saberes e aos valores adquiridos no pré-serviço, compõem um saber plural que se faz necessário na prática docente.

Nos relatos das professoras que tiveram experiências anteriores à carreira, evidenciou-se que, no desenvolvimento da sua prática, elas recordavam como as professoras organizavam suas atividades, como elas agiam diante do inusitado e procuravam seguir seu exemplo, pois acreditavam que elas eram "modelos" a serem seguidos. Para Tatiana, os seus conhecimentos práticos foram aprendidos vendo uma professora ensinar, pois, durante três anos, ela ajudou a mesma professora como amiga 
da escola: “[...] eu até aplico, porque ela dava aula pro $2^{\circ}$ período e eu também dou aula pro $2^{\circ}$ período. Muita coisa assim eu me lembro dela e eu aplico na sala de aula com meus meninos." Para Mariano (2005), é comum os professores buscarem nos professores mais antigos a referência de um trabalho bem sucedido, referenciando-os como "mestre-modelo".

Nos relatos das professoras Gisele e Rita, que também tiveram experiência docente antes, nota-se que a inserção não foi tão complexa quanto para as outras que nada conheciam do contexto da sala de aula. Elas reconheceram que esse contato junto com uma professora experiente foi algo positivo e ajudou tanto em relação ao cumprimento de aspectos burocráticos (como preenchimento de diários) quanto para que elas não tivessem "medo" e também para que elas tivessem noção do que deveria ser feito:

(4) Porque eu comecei a trabalhar com quinze anos em uma creche. A gente lida com as dificuldades do dia a dia da criança. A gente observa aquilo e vai amadurecendo para ver como lidar com aquelas situações. Então, antes do primeiro impacto na Educação Infantil, eu já tive experiências vivenciadas com crianças até menores. Então, acho que foi uma experiência muito boa pra mim (Gisele).

(5) Isso eu fui vendo quando substitui outra professora aqui, porque eu fiquei uma semana com ela na sala antes dela sair. Depois fiquei um mês na sala dela, então, o que deu pra mim sugar eu ia perguntando, interrompia, perguntava e anotava. Foi ótimo! Eu aproveitei bastante, porque eu não tinha contato com Educação Infantil, era completamente diferente de onde eu dava aula, mudou da água pro vinho mesmo, muito diferente (Rita).

Essa experiência pregressa é também localizada pelos professores nas atividades de estágio curricular que vivenciaram durante o processo de formação inicial. Elas relataram que, nos estágios, foi possível aprender sobre a prática e o cotidiano da sala de aula. Para Tânea “[...] o que você vê em sala de aula não é a prática, nunca é, porque quando eu fiz faculdade era muito mar de rosas, a prática é totalmente diferente e quando eu fui fazer estágio eu realmente vi como é a prática”.

Para a professora Gisele, os estágios, além de promoverem o contato com uma sala de aula real e proporcionarem aprendizagens sobre a prática da profissão, foram também importantes para que ela se identificasse com um determinado segmento de ensino: “[...] foi após esse estágio que eu realmente vi que estava apta a ser profissional da Educação Infantil. Foi durante meus estágios que eu consegui distinguir, aí falei assim: eu quero Educação Infantil". Analisando seu depoimento, observa-se ainda o seu 
medo de ser julgada pela falta de experiência no primeiro ano da docência; no entanto, ela considerava os seus estágios como experiências e essa convicção a ajudou a se sentir mais segura, caso fosse questionada por algum pai ou responsável por seus alunos.

Enquanto para a professora Gisele o aprendizado da prática aconteceu apenas durante os estágios, para a professora Tatiana, os relatos de experiência de um professor em sua faculdade também foram considerados por ela como ensinamentos práticos. Segundo Tatiana, esse professor "[...] contava os casos dele, o que acontecia na escola, ele vinha contava, falava a decisão que ele tinha tomado. Aí assim, quando chegava a acontecer com a gente, a gente acaba lembrando".

$\mathrm{Na}$ busca por conhecimentos práticos que favoreçam a docência, as professoras relataram que o papel da atividade de observação realizada no estágio contribuiu para que elas fossem se apropriando dos saberes profissionais pelas diversas experiências vivenciadas. A professora Marta relata que, quando foi estagiária, viu a professora regente da turma vivenciando uma situação conflituosa relacionada à sexualidade infantil e, naquele momento, pensou que não saberia como agir, mas a atitude da docente foi marcante "[...] e eu aprendi que a gente não pode fazer uma tempestade em copo d'agua, eu fiquei assustada, mas graças a Deus eu não tive esse problema ainda não".

Já para Sueli, a falta de experiência anterior e de algum contato com a escola ou com crianças pequenas foi a razão pela qual ela se sentiu "[...] totalmente perdida, porque eu nunca tinha entrado numa sala de aula, nem para observar nem nada, nem curiosidade nem nada. Então eu fiquei totalmente perdida". Segundo Sueli, em seu município, admitia-se que as professoras em formação assumissem a sala de aula. Como ela estava precisando de um emprego, matriculou-se em um curso de graduação para garanti-lo. Outra observação interessante é que o seu primeiro contato com a sala de aula ocorreu antes mesmo de ela realizar algum estágio do curso, pois, quando assumiu a sala de aula, estava no início do curso e

(6) [...] estágio está sendo mais agora no finalzinho. Eu vou formar ano que vem. Então, está sendo mais agora. Que nem esse mês mesmo eu estou fazendo estágio com a Educação Infantil, só que como eu estou dando aula, eu estou fazendo na minha sala sabe? De observação. Então, agora que eu estou tendo oportunidade de observar, mas mesmo assim eu já estou na prática. 
O depoimento de Sueli revela uma situação singular e nos faz questionar: como uma estudante estagiária pode observar a própria experiência? Qual é a orientação que ela recebe da sua faculdade sobre a realização do estágio? Será que observar a própria experiência contribui para uma formação prática significativa?

Para Gatti (2009, p.96), os estágios nos cursos de licenciatura têm apresentado problemas críticos, pois, na maioria deles, tanto a sua programação quanto o seu controle têm sido precários sendo permitido muitas vezes "[...] uma simples observação de aula". E ainda existem outros entraves como: muitas escolas não têm disponibilidade para aceitarem os estagiários e, quando aceitam, nem sempre permitem que eles se envolvam nas atividades de ensino; falta uma articulação entre os cursos de licenciatura e as redes de ensino para criarem projetos institucionais de estágio; na maioria das escolas, não há acompanhamento das atividades de estágio por um supervisor e, como muitos alunos trabalham o dia todo e optam pelos cursos no turno da noite, faltando tempo para cumprirem as horas exigidas pelo estágio (GATTI, 2009, p. 96). Já para Pimenta (2010), o estágio precisa acompanhar essa nova realidade, esse novo perfil de professores que está surgindo e, para isso, sugere uma proposta de estágio que possa atendê-los. Para a autora, tem sido cada vez mais frequente o retorno de professores experientes às salas de aula na universidade e o início do exercício do magistério antes do término da licenciatura, pois muitos professores estão encontrando a possibilidade de complementar a formação acadêmica exigida pela legislação.

Diante das exigências da legislação e considerando que muitos estudantes dos cursos de licenciatura já são professores e trabalham em dois - e às vezes até três expedientes e que alguns já estão, inclusive, perto da aposentadoria, Pimenta (2010) propõe que o estágio, nesses casos, seja visto como uma “[...] possibilidade de ressignificação da identidade e numa proposta de formação contínua” (p. 126).

Dessa forma, a referida autora sinaliza que os professores-alunos, aqueles que já exercem o magistério, mas que estão cursando a graduação

[...] investiguem a própria atividade pedagógica, e com isso, transformem seu saber fazer docente numa contínua construção e reconstrução de suas identidades a partir da significação social da profissão, bem como pelo significado que cada professor confere a docência em seu cotidiano e nas relações com seus pares em escolas, associações, sindicatos e outros agrupamentos (PIMENTA, 2010, p. 140). 
Ainda segundo Pimenta (2010), o estágio para quem já está exercendo o magistério deve considerar as experiências vivenciadas pelo professor e prezar pela ressignificação dos saberes da prática docente, criando possibilidades para que as propostas pedagógicas e as teorias sejam "tiradas do papel”. E, ainda, que seja um “[...] espaço de diálogo e de lições, de descobrir caminhos, de superar os obstáculos e construir um jeito de caminhar na educação, de modo a favorecer resultados de melhores aprendizagens dos alunos" (PIMENTA, 2010, p.129).

Para a referida autora, a finalidade do estágio é proporcionar a aproximação do aluno com a realidade que ele atuará, já que se trata de um "retrato vivo" da prática docente. Além disso, a autora aponta que o estágio deve ser visto como um espaço privilegiado de questionamento e investigação, bem como um momento de interação e ação entre a universidade e a escola. No entanto, sabemos que, assim como Sueli, outros professores também vivenciaram e vivenciam a situação de realizarem o estágio mesmo já exercendo o magistério e, por isso, optam por realizaram em sua sala de aula.

Vale ressaltar ainda que existem os modelos de formação de grande parte dos cursos superiores que oferecem o estágio, ou seja, promovem a inserção na escola no final dos cursos. Esses modelos têm levado os estudantes a verem os estágios curriculares de forma desarticulada da teoria, sendo interpretado como uma atividade independente, como um momento de aplicar os conteúdos adquiridos ao longo do curso nas últimas etapas para um cumprimento obrigatório e burocrático de sua formação inicial. Assim, os estágios não têm sido considerados, para muitos estudantes, professores e pesquisadores, como um momento e um espaço de reflexão, investigação e pesquisa.

\section{CONSIDERAÇÕES FINAIS}

Os depoimentos apresentados neste estudo apontam que os anos iniciais da docência não têm sido pensados de forma a facilitar o trabalho do professor iniciante, não levando em consideração o fato de que esse grupo tem pouca experiência, pode-se sentir que estão despreparadas para atuarem na sala de aula, sentimentos como insegurança, medo e angústia se tornam comuns e que precisam de um acompanhamento para desenvolver com êxito a prática educativa. Esse acompanhamento inicial deve ser organizado de forma a amenizar a complexidade dos 
primeiros anos da docência, contribuindo para que os professores se sintam orientados sobre a sua prática. Acredita-se que os programas de inserção a docência, presentes em alguns países da Europa e apresentados por Garcia (1999), são bons modelos a serem seguidos, embora se saiba que eles precisam ser estruturados considerando a realidade das escolas brasileiras.

Evidencia se também que as professoras, apesar de ficarem entusiasmadas e se sentirem realizadas por terem conseguido iniciar a vida profissional docente, também se deparam com alguns desafios como: a falta de acolhimento e orientação do trabalho, a necessidade de pedir ajuda aos pares e a sensação de estarem despreparadas para essa função, pois se sentem "perdidas" para elaborar o planejamento e as atividades cotidianas da sala aula. Os relatos evidenciam que as professoras não sabem o que devem ensinar e se o que estão ensinando está adequado para a faixa etária que estão trabalhando. Nos relatos coletados, as professoras evidenciaram que é dentro da escola, com os professores que trabalham com turmas com faixa etária próximas que a socialização entre os pares se efetiva melhor. Essa socialização se estabelece num processo de interação entre os pares devido à proximidade das turmas e também pela necessidade de resolver problemas imediatos que somente quem está acostumado a vivenciar tem conhecimento de como resolver de forma mais adequada. Sendo assim, o processo de socialização entre pares contribui para que os sujeitos vivenciem da melhor maneira de ensinar e aprender, além de oferecer segurança ao professor nesta etapa do desenvolvimento profissional.

Ressalta-se, também, que os depoimentos das professoras mostram que as experiências vivenciadas na sala de aula, seja como estagiárias ou voluntárias, são momentos que facilitam o início do desenvolvimento profissional e ajudam a amenizar os sentimentos negativos expressados pela maioria dos professores iniciantes. Evidenciam, também, a necessidade de se pensar em mais momentos de contato com o fazer pedagógico, de possibilitar que os professores, antes de assumirem a sala de aula sozinhos, tenham contato com professores experientes e possam observá-los. Os depoimentos das professoras mostram que essa rede de relações no cotidiano, na qual a socialização ocorre com diversos sujeitos da escola e fora dela, favorece para que os professores aprendam sobre o trabalho docência de forma menos sofrida. 


\section{REFERÊNCIAS}

GARCIA, C. M. Formação de professores: para uma mudança educativa. Porto: Porto, 1999.

Pesquisa sobre a formação de professores: o conhecimento sobre aprender a ensinar. Tradução de Lólio Lourenço de Oliveira. Revista Brasileira de Educação, n. 9, p. 51-75, 1998.

GATti, B. A.; BARreto, E. S. S.; ANDRÉ, M. D. A. Políticas docentes no Brasil: um estado da arte. - Brasília: UNESCO, 2011. Disponível em: $\langle$ http://unesdoc.unesco.org/images/0021/002121/212183por.pdf $>$. Acesso em: $14 \mathrm{fev}$. 2012.

HARGREAVES, A. Os professores em tempos de mudança. Portugal: MC GRaw Hill, 1998.

LICHTENECKER, M. S. Desenvolvimento profissional de professores principiantes e os movimentos para a assunção da profissão docente. 2010. $252 \mathrm{f}$. Dissertação (Mestrado em Educação) - Universidade Federal de Santa Maria, Santa Maria, RS, 2010.

LIMA, E.F A construção do início da docência: reflexões a partir de pesquisas brasileiras. 2004. Disponível em: 〈http://coralx.ufsm.br/revce/revce/2004/02/a6.htm>. Acesso em: 27. nov. 2011.

LIMA, E. F. de. (Org.). Sobrevivências no início da docência. Brasília: Líber Livro Editora, 2006.

MIZUKAMI, M. G. N.; REALI, A. M. M. R.; REYES, C. R.; MARTUCCI, E. M.; LIMA, E. R.; TANCREDI, R. M. S. P.; MELO, R. R. Escola e aprendizagem da docência: processos de investigação e formação. São Carlos. EdUFSCar, 2002.

PERRENOUD, P. A prática reflexiva no ofício de professor: profissionalização e razão pedagógica. Porto Alegre: Artmed editora, 2002.

PIMENTA, S. G. O estágio na formação de Professores: Unidade teoria e prática. 9. ed. São Paulo: Cortez, 2010.

TARDIF, M. Saberes docentes e formação profissional. 2. ed. Petrópolis: Vozes, 2002 